\title{
The $\{111\}$-Modulated Domains in Tetragonal $\mathrm{BaTiO}_{3}$
}

\author{
Yu-Chuan $\mathrm{Wu}^{\ddagger}$ and Hong-Yang $\mathrm{Lu}^{*, \dagger}$ \\ Centre for Nanoscience Institute of Materials Science and Engineering, National Sun Yat-Sen University, \\ Kaohsiung, Taiwan \\ Daniel E. McCauley* and Mike S.H. Chu*
}

Ferro Electronic Material Systems, Penn Yan, New York, USA

\begin{abstract}
Barium titanate $\left(\mathrm{BaTiO}_{3}\right)$ base-metal electrode multilayer ceramic capacitors of an X7R-formulation, sintered at $1200^{\circ} \mathrm{C}$ under low oxygen partial pressures $\left(\right.$ of $p \mathrm{O}_{2} \approx 10^{-9}$ and $10^{-11}$ atm, respectively), followed by annealing at $1000^{\circ} \mathrm{C}$ in an atmosphere containing a higher oxygen partial pressure (of $\left.\mathrm{pO}_{2} \approx 10^{-5}-10^{-6} \mathrm{~atm}\right)$, have been analyzed for crystalline phases using X-ray diffractometry, for microstructure using transmission electron microscopy, and for microchemistry using energy-dispersive $X$-ray spectroscopy and electron energy loss spectroscopy. The classical core-shell structure characterized by a core consisting of tetragonal ferroelectric $\{011)$ domains and featureless shell (designated type I) was observed only in sample A sintered in $\mathrm{pO}_{2} \approx 10^{-9} \mathrm{~atm}$. For sample $\mathrm{B}$ sintered in $\mathrm{pO}_{2} \approx 10^{-11} \mathrm{~atm}$, the core-shell structure is predominantly type II, consisting of a featureless shell similar to type I, but a core of modulated domains. The core of type II contained incommensurately modulated $\{111\}$ superlattice domains along $\langle 111\rangle$. The superlattice can be described by a displacive modulation with incommensurate wave vectors $\mathbf{k}_{1}=0.58 \mathrm{a}^{*}, \mathbf{k}_{2}=$ $0.58 b^{*}$, and $k_{3}=0.58 c^{*}$. It is due to the ordering of defect associates $\left(\mathrm{Ti}_{\mathrm{Ti}}^{\prime}, V_{\mathrm{O}}^{\bullet \bullet}\right)^{\bullet}$, generated extrinsically from sintering in low $\mathrm{pO}_{2}$. Shell thickness was determined by the lattice diffusion of $\mathrm{Ca}^{2+}$ solute cations into $\mathrm{BaTiO}_{3}$ grains during sintering. The core-shell interface became less distinguishable in type II because defect associates $\left(\mathrm{Ti}_{\mathrm{Ti}}^{\prime}, V_{\mathrm{O}}^{\bullet \bullet}\right)^{\bullet}$, unlike those in type $\mathrm{I}$, were not completely eliminated by re-oxidizing in $p \mathrm{O}_{2} \approx 10^{-5}-10^{-6}$ atm, but became ordered along $\langle 111\rangle$ and gave rise to structural modulation.
\end{abstract}

\section{Introduction}

$\mathrm{T}$ HE Barium titanate $\left(\mathrm{BaTiO}_{3}\right)$ powder with acceptor ${ }^{1-3}$ and amphoteric dopants ${ }^{3,4}$ according to the X7R formulations produces multilayer ceramic capacitors (MLCCs) of temperature stability within $\pm 15 \%$ of the room-temperature capacitance in the range of $-55^{\circ}$ and $+125^{\circ} \mathrm{C}$. Making to MLCCs when adopting Ni base-metal electrodes (BME), the ceramicmetal thin-layer stacks are typically sintered at $\sim 1200^{\circ} \mathrm{C}$ at a low oxygen partial pressure between $\sim 10^{-9}$ and $10^{-11} \mathrm{~atm} .^{3,5-8}$ Sintering is often conducted with $\sim 1-2 \mathrm{wt} \%$ of liquid-phase additives, e.g., $\mathrm{BaO}-\mathrm{SiO}_{2}{ }^{9}$ Oxygen vacancies, possessing two positive effective charges when fully ionized, generated extrinsically in low $p \mathrm{O}_{2}$, played a crucial role in the long-time failure of MLCCs. Failure of the capacitors was believed ${ }^{9-12}$ to occur by a degradation mechanism when such vacancies migrated toward

H. Chan-contributing editor

Manuscript No. 21074. Received October 15, 2005; approved April 6, 2006.

*Member, American Ceramic Society.

Author to whom all correspondence should be addressed. e-mail: hyl@mail.nsysu. edu.tw

${ }^{\ddagger}$ Present address: Department of Materials and Mineral Engineering, National Taipei University of Technology, Taipei 10608, Taiwan. the cathode. The degradation in insulation resistance was dependent kinetically on the time, electric field, and temperature.

The extrinsic oxygen vacancies had been thought ${ }^{3,4,10}$ to be randomly distributed within the dielectric layers until transmission electron microscopy (TEM) microstructure analysis revealed $^{5-8}$ that the long-range ordered, modulated structure along $\langle 111\rangle$ was associated with these vacancies in $\mathrm{BaTiO}_{3}$ grains. Oxygen vacancies were usually reported to exist along the twin boundaries of the $\{111\}$ growth twins ${ }^{13,14}$ in pressureless-sintered ceramics and the $\{111\}$ nanotwins ${ }^{15}$ in $\mathrm{BaTiO}_{3}$ thin films. Two crystal parts are related by sharing the $\{111\}$ twin plane where corner-sharing $\mathrm{TiO}_{6}$ octahedra in aristotype cubic $\mathrm{BaTiO}_{3}$ has changed to face-sharing $\mathrm{Ti}_{2} \mathrm{O}_{9}$ groups. ${ }^{13-15}$ Reduction of $\mathrm{Ti}^{4+}$ to $\mathrm{Ti}^{3+}$ occurred ${ }^{13}$ in the ceramic, with oxygen vacancies being the principal charge-compensation defect generated extrinsically on the $\mathrm{O}(1)$ site ${ }^{16}$ of the $\mathrm{BaO}_{3}\{111\}$ planes. Almost all $\mathrm{BaTiO}_{3}$ grains in X7R-formulated capacitors ${ }^{5-8}$ were characterized by the classical core-shell structure, ${ }^{8,17-22}$ which is directly connected to the dielectric behavior. Recent microstructure observations ${ }^{5-8}$ conducted on dc-degraded $\mathrm{BaTiO}_{3}-\mathrm{BME} \mathrm{MLCC}$ have suggested that the origin of degradation lies with the ordering of high-concentration oxygen vacancies in the core region of the core-shell structure. Further, re-oxidation at lower temperatures in an oxygen partial pressure higher than that in the sintering atmosphere has effectively eliminated ${ }^{7}$ the $\{111\}$ structural modulations, and linear defects with the total insulation resistance of capacitors improved; the types of defects were nevertheless not specified.

In this study, efforts were concentrated on analyzing the development of core-shell in X7R-formulated $\mathrm{BaTiO}_{3}$ BMEMLCCs. We have looked into the microstructure in order to elucidate how oxygen partial pressure in the sintering atmosphere has affected the formation and characteristics of coreshell. Two batches of MLCC chips were sintered at $1200^{\circ} \mathrm{C}$ in $\sim 10^{-9}$ and $\sim 10^{-11}$ atm of oxygen partial pressures, respectively, and subjected to a similar re-oxidation step at $1000^{\circ} \mathrm{C}$ in $p \mathrm{O}_{2} \approx 10^{-5}-10^{-6} \mathrm{~atm}$. Based on observations and argued from possible defect reactions, a model is proposed to illustrate schematically how the core-shell structure and the modulated core have evolved.

\section{Experimental Procedure}

MLCC chips based on an X7R formulation shown in Table $\mathrm{I}^{23}$ using $\mathrm{BaO}-\mathrm{CaO}-\mathrm{SiO}_{2}$ as a liquid-phase sintering additive, were sintered in two successive stages. First, sintering was conducted at $1200^{\circ} \mathrm{C}$ for $2 \mathrm{~h}$ under a reducing atmosphere containing oxygen at $p \mathrm{O}_{2} \approx 10^{-9}$ and $10^{-11}$ atm for samples $\mathrm{A}$ and $\mathrm{B}$, respectively, and both were followed by annealing at $1000^{\circ} \mathrm{C}$ in $p \mathrm{O}_{2} \approx 10^{-5}-10^{-6} \mathrm{~atm}$ for $4 \mathrm{~h}$. Crystalline phases in sintered samples were identified by X-ray diffractometry (XRD) using a Siemens D5000 diffractometer (Karlsruhe, Germany) with $\mathrm{CuK \alpha _{1+2 }}$ radiation and a Ni filter, operating at $40 \mathrm{kV} / 30 \mathrm{~mA}$. 
Table I. Composition Range for X7R Formulated MLCC Chips $^{23}$

\begin{tabular}{lc}
\hline Component & Range (mol \%) \\
\hline $\mathrm{BaTiO}_{3}$ & $95-97$ \\
$\mathrm{CaTiO}$ & $1-3$ \\
$\mathrm{BaO}$ & $0.25-1.25$ \\
$\mathrm{CaO}$ & $0.01-0.5$ \\
$\mathrm{SrO}$ & $0-0.5$ \\
$\mathrm{SiO}_{2}$ & $1-3$ \\
$\mathrm{MnO}_{2}$ & $0.05-0.5$ \\
$\mathrm{Y}_{2} \mathrm{O}_{3}$ & $0.2-2$ \\
$\mathrm{CoO}$ & $0.03-0.25$ \\
\hline
\end{tabular}

MLCC, multilayer ceramic capacitors.

Two TEMs were used to characterize the sintered microstructure: a JEOL ${ }^{\mathrm{TM}}$ AEM 3010 (Tokyo, Japan) equipped with energy-dispersive spectroscopy (EDS, Link Systems, Oxford Instruments, Oxford, UK) and operating at $300 \mathrm{kV}$, and a Tecnai $^{\mathrm{TM}} \mathrm{G}^{2}$ F20 (FEI, Hillsboro, OR) energy-filtered fieldemission microscope (FEG-TEM) equipped with both EDS (EDAX, Mahwah, NJ) and parallel electron energy loss spectroscopy (PEELS, Gatan, Pleasanton, CA) and operating at 200 $\mathrm{kV}$. Thin foils were prepared by conventional mechanical grinding, polishing, and ion beam thinning to electron transparency. As-sintered chips (of $\sim 1200 \mu \mathrm{m}$ thick) were ground on both sides to approximately half of the thickness before polished using diamond lapping films (3M, St Paul, MN) successively to an $\sim 1 \mu \mathrm{m}$ surface roughness and $\sim 10 \mu \mathrm{m}$ thickness. Thin sections were carefully stuck onto $\mathrm{Cu}$ rings using $\mathrm{G} 1$ glue before being Ar -ion beam thinned to electron transparency using a Gatan ion miller (DuoMill ${ }^{\mathrm{TM}}$ or PIPS ${ }^{\mathrm{TM}}$, Gatan, Pleasanton, CA).

High-resolution images were contrast enhanced using fast Fourier transform (FFT) of DigitalMicrograph ${ }^{\mathrm{TM}}$ (Gatan).

\section{Results}

Sintered samples contained predominantly tetragonal ( $t$-) BaT$\mathrm{iO}_{3}$ (JCPDS 5-626), Ni (JCPDS 4-085), and $\mathrm{Cu}$ (JCPDS 4-836) from the electrodes, as shown in traces (a) and (b) of Fig. 1 for both batches of samples. The existence of a second phase, determined ${ }^{24}$ to be $\mathrm{Ca}_{2} \mathrm{Y}_{8} \mathrm{Si}_{6} \mathrm{O}_{26}$ (hexagonal, $P 6_{3} / m$ (no. 176)) by selected area diffraction patterns (SADPs), coupled with chemical analysis, is registered by the reflection peak at $2 \theta \approx 29^{\circ}$, as arrowed.

A representative microstructure under optical microscopy $(\mathrm{OM})$ is shown in Fig. 2 for sample A where each layer of the $\mathrm{BaTiO}_{3}$ dielectrics and Ni electrodes $\sim 4.5$ and $\sim 2.4 \mu \mathrm{m}$ thick, respectively, can be easily identified. Residual pores along the $\mathrm{Ni}$ electrode layers, as indicated, suggest incomplete densification. Sample B also exhibited a similar microstructure.

\section{(1) Microstructure of Sample A (Sintered in $\left.\mathrm{pO}_{2}=10^{-9} \mathrm{~atm}\right)$}

Grains in the $\mathrm{BaTiO}_{3}$ dielectric layers are represented by the classical core-shell structure ${ }^{3,17-22}$ (Fig. 3(a)), a paraelectric, featureless shell, and a ferroelectric core showing the ferroelectric domains, with a triple grain junction containing residual glassy phase. The core in grain $A_{1}$ was characterized by boundary fringes representing the $90^{\circ}\{011)_{t}$ ferroelectric domains, ${ }^{25-27}$ where $t$ stands for tetragonal, while the shell (of $\sim 120 \mathrm{~nm}$ ) appeared featureless under TEM. The core-shell boundary exhibited distinctive crystallographic faceting along $\{100\}_{p c}$ and $\{110\}_{p c}$, where $p c$ denotes pseudo-cubic, as shown in Fig. 3(b). The crystallographic faceting formed at sintering temperatures is consistent with those found ${ }^{28}$ before with residual pores in BaT$\mathrm{iO}_{3}$ sintered in air. Such a core-shell structure similar to those reported $^{17-22}$ before is designated type I. Microchemical analysis (Fig. 3(c) with probe positions indicated in high-angle annular dark-field (HAADF) image in the inset) across grain $\mathrm{A}_{1}$ revealed

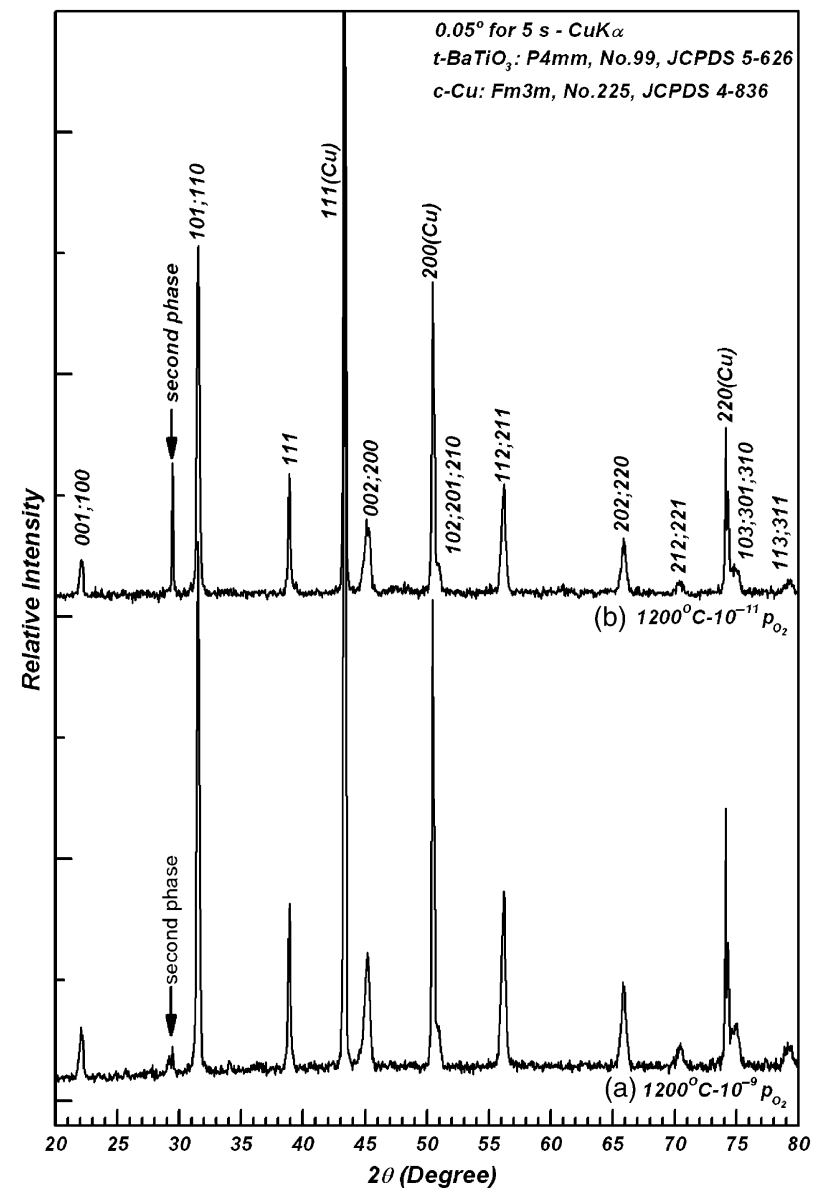

Fig. 1. X-ray diffractometry traces for sintered multilayer ceramic capacitors chips, (a) sample A sintered in $p \mathrm{O}_{2} \approx 10^{-9}$ atm, and (b) sample $\mathrm{B}$ sintered in $p \mathrm{O}_{2} \approx 10^{-11}$ atm showing second phase (as indicated).

additives including acceptors, $\mathrm{Ca}, \mathrm{Co}, \mathrm{Y}$ (dual roles ${ }^{4}$ ), and sintering aid $\mathrm{Si}, \mathrm{Ca}$ was detected to concentrate in the shell (i.e., points 1, 2, and 5) when the core (i.e., points 3 and 4) did not exhibit any $\mathrm{Ca}$ peak. This core-shell interface in the vicinity indicated by the pointer is resolved by high-resolution imaging,

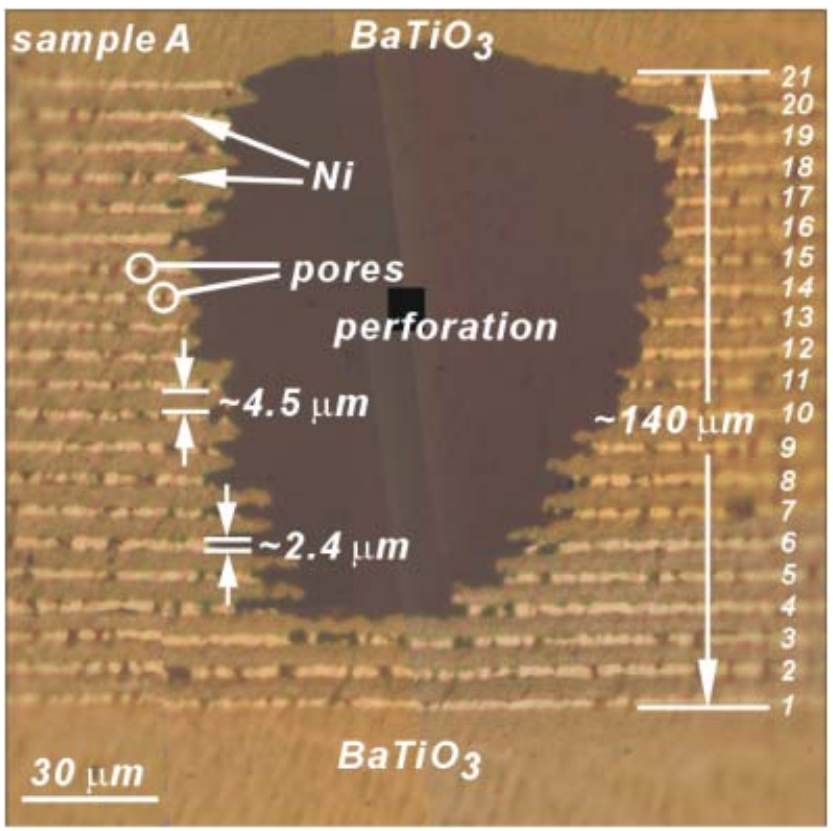

Fig. 2. Representative cross-section microstructure showing $\mathrm{BaTiO}_{3}$ dielectric and Ni electrode layers (optical microscopy). 

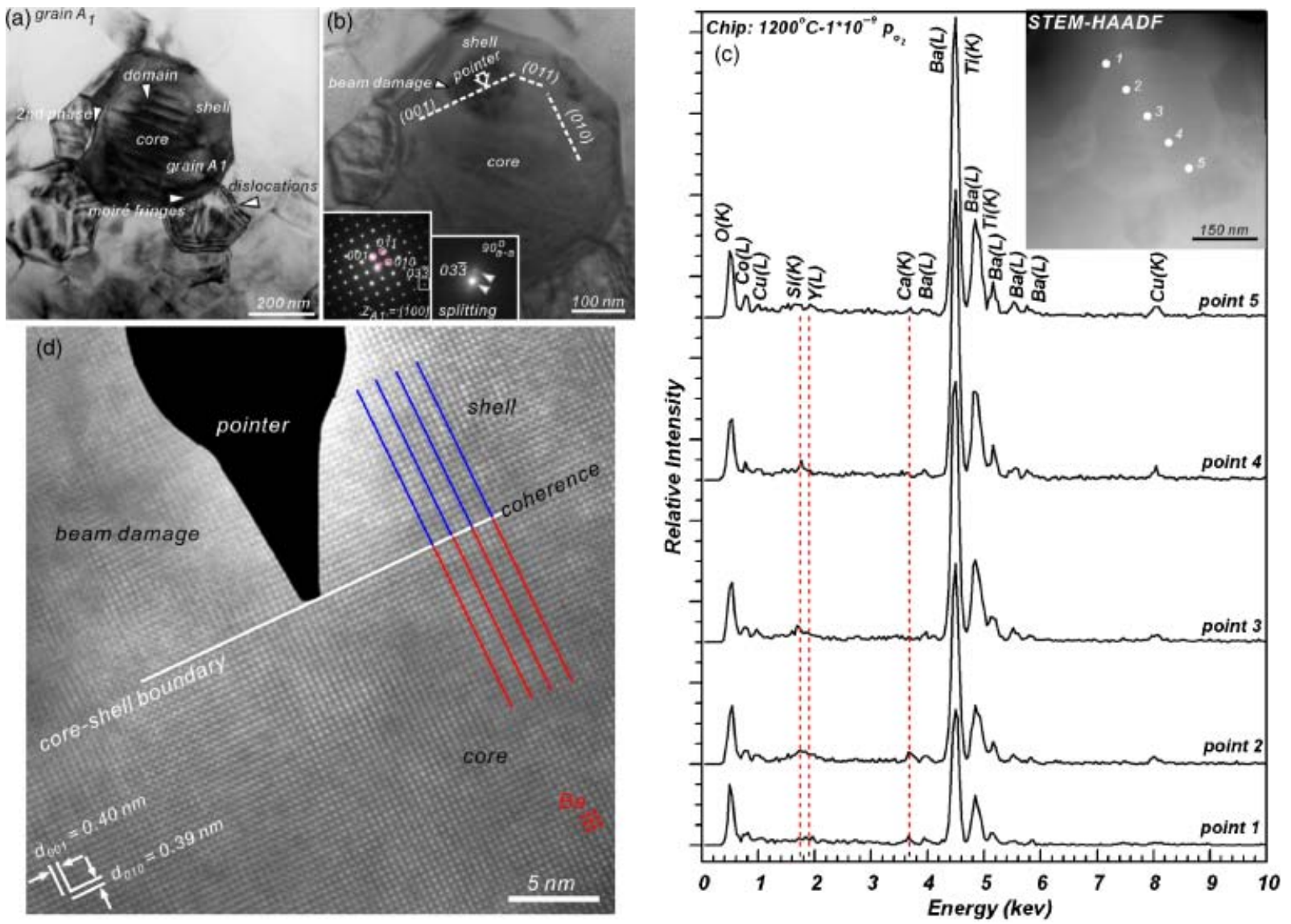

Fig. 3. Type I core-shell structure in sample A, bright field images of grain $A_{1}$ showing (a) ferroelectric core and paraelectric shell, (b) facetted coreshell interface with corresponding selected area diffraction patterns inset, (c) energy-dispersive spectroscopy spectra showing acceptor dopants, and (d) core-shell interface revealed by high-resolution imaging (transmission electron microscopy).

as shown in Fig. 3(d). No absence of the $\mathrm{BaO}_{3}$ columns ${ }^{29}$ was detected in the field of view (i.e., bright dots in Fig. 3(d)), while the lattice fringes being uninterrupted (indicated) suggests a coherent interface containing no perfect dislocations ${ }^{20}$ along $\langle 001\rangle_{p c}$ and $\langle 011\rangle_{p c}$. The white line indicating the core-shell boundary does not indicate the exact interface position.

Ferroelectric domains (Figs. 4(a) and (b)) and wavy microstructure (Fig. 4(c)) showing long-range fluctuations ${ }^{30}$ were observed from within the core of a growing grain $\left(\mathrm{A}_{2}\right)$ with 10 -side concave boundaries. The core is also characterized by domain fringes (Fig. 4(c)), but the domains are no longer the ferroelectric $\{011)_{t}^{25-27}$ judging from the $g$ vectors in corresponding SADP. The core had lost its waviness upon reaching the coreshell boundary. These domains were inclined to $Z=[\overline{1} 11]$ when the boundary fringes (indicated in Fig. 4(c)) were visible. Tilting to $g=01 \overline{1}$ of $\mathrm{Z}=[011]$, although the core-shell boundary was still distinguishable, the core itself had become less distinctive (Figs. 4(b) and (c)). At higher magnifications, it was revealed that the domain fringes subtending an angle of $\sim 71^{\circ}$ (or $109^{\circ}$ ) and lying parallel to $(\overline{1} 1 \overline{1})$ and (11) were undulating. The separation between domain fringes suggests a much finer domain size of $\sim 5 \mathrm{~nm}$ (Fig. 4(c)) than the $\{011)_{t}$ ferroelectric twins of tens of micrometers in size. ${ }^{25,26}$ Nevertheless, the existence of a featureless shell is unambiguous. Such a grain structure with an indistinctive core-shell interface in contrast to that reported ${ }^{17-22}$ before is designated type II. A significantly higher concentration of $\mathrm{Ca}$ (indicated) was again registered in the shell, as shown by electron energy loss spectroscopy (EELS) (Figs. 4(d) and (e)).

\section{(2) Microstructure of Sample B (Sintered in $\left.\mathrm{pO}_{2}=10^{-11} \mathrm{~atm}\right)$}

Sample A contained a mixture of both types I and II core-shell. However, sample B contained predominantly type II where the core-shell interface was not readily differentiated under the microscope. A typical microstructure is shown in Fig. 5(a); only when the foil was tilted to two-beam conditions did the core become visible. Although HAADF imaging revealed other microstructure features, e.g., dislocations, triple-grain junctions, as shown in Fig. 5(b) for grain $\mathrm{B}_{1}$, the core-shell boundary could not be distinguished unambiguously. Apparently, $\mathrm{Ca}$ of atomic number $Z=20$ and $\mathrm{Ti}$ of $\mathrm{Z}=22$ are not resolved by atomic contrast under such imaging conditions.

Grain $\mathrm{B}_{2}$, also containing a core-shell, is shown in Fig. 6(a); unlike that in Fig. 3(a), the ferroelectric domains were not readily discerned. The corresponding SADP, shown in the inset, revealed incommensurate side-band (or satellite) spots around the fundamental reflections along $\langle 11 \overline{1}\rangle$ as indicated. The featureless shell exhibited typical atomic images projected on (011) where the Ti columns ${ }^{31}$ were discerned, as depicted in the schematic illustration inset in Fig. 6(b). A disordered (or amorphized) region near the foil edge, where structure relaxation occurred, ${ }^{32}$ or beam-induced loss of oxygen, ${ }^{33}$ resulting in the background ring pattern (as arrowed in the pattern simulated by FFT), has also been resolved in the image.

The core in grain $\mathrm{B}_{2}$ appeared modulated along $\langle 11 \overline{1}\rangle$ as indicated in Fig. 6(a); the modulated structure composed of a basic structure and a superlattice is better discerned by the highresolution image in Fig. 6(c). The basic structure, i.e., $t-\mathrm{BaTiO}_{3}$, is superimposed by a periodic modulation at a wavelength of $\lambda \approx 2.314 \mathrm{~nm}$ (i.e., $(\Delta g)^{-1}$ when $\alpha \approx 0.1 g$ as determined from corresponding SADP) where an ordered superlattice structure along $\langle 11 \overline{1}\rangle$ is realized. FFT-simulated diffraction pattern (inset) also reveals a series of satellite spots that indicates ${ }^{34-37}$ a periodic distortion incommensurable with the basic structure (i.e., tetragonal $P 4 m m$ (no. 99)), i.e., the fluctuations are not simple multiples of the unit cell of the basic structure. Structural modulation has occurred at an interval of $\sim 10$ times of $d_{11 \overline{1}}$ 

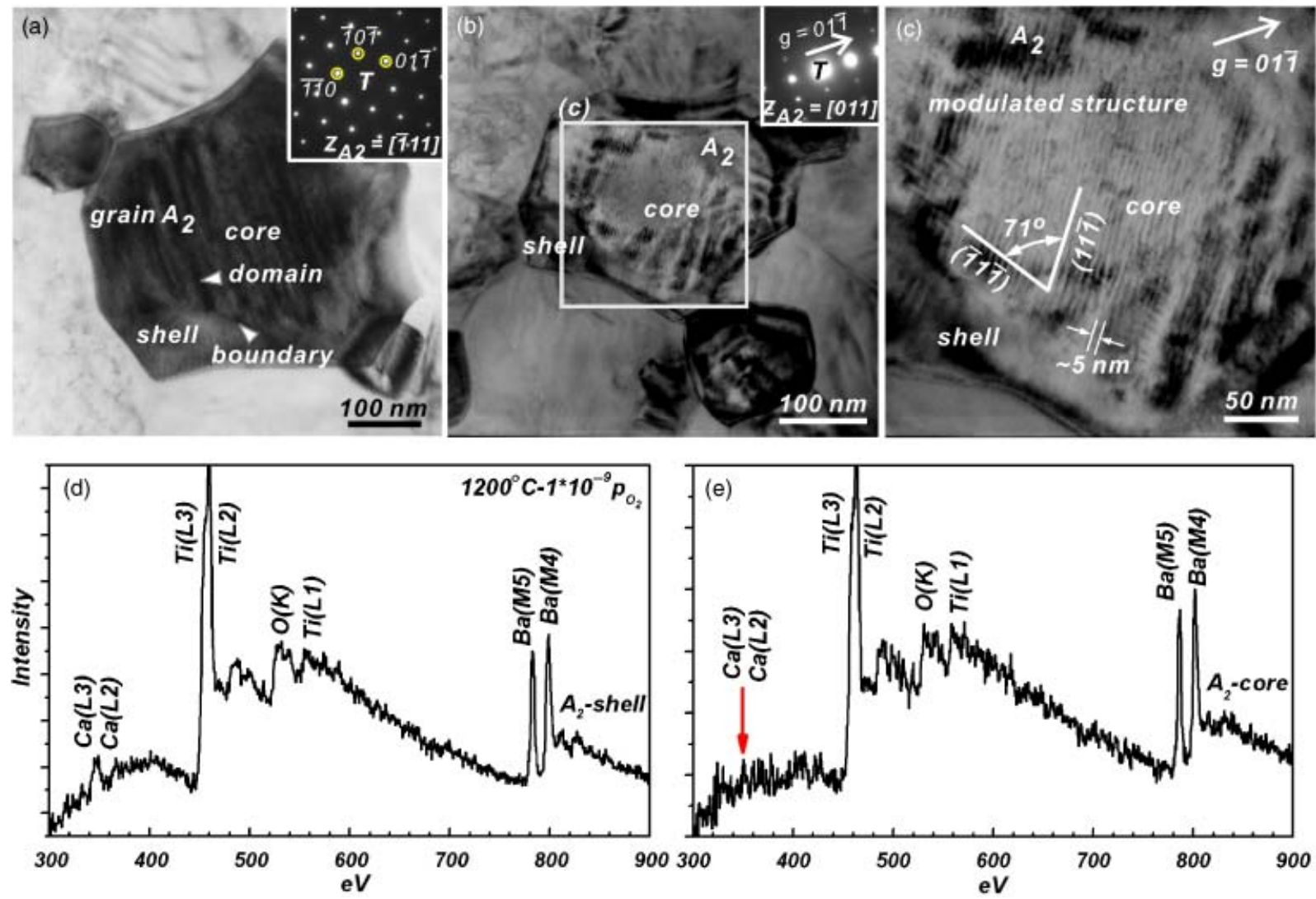

Fig. 4. Type II core-shell structure in sample A, bright field images of grain $\mathrm{A}_{2}$ showing (a) core with fringes and a paraelectric shell with corresponding selected area diffraction patterns inset, (b) modulated core, (c) modulated domains lying in (111) and (11) , (d) electron energy loss spectroscopy spectra showing higher $\mathrm{Ca}$ in shell, and (e) lower in core (transmission electron microscopy).

$(=0.2314 \mathrm{~nm})$. The periodicity describes defect clustering ${ }^{35-37}$ that has given rise to the modulated structure. The region appearing bright when imaged under slightly underfocus conditions (i.e., $\Delta z>0$ from Scherzer defocus) indicates strains because of local lattice relaxation. ${ }^{35,36}$ Lattice relaxation and the compensating expansion in the rest of the structure were thought $t^{5-8}$ to be associated with the ordering of defect clusters containing oxygen vacancies, ${ }^{6}$ similar to defect clustering in $\mathrm{Fe}_{1-x} \mathrm{O} .^{35-37}$

Similar to grain $\mathrm{A}_{2}$ (Fig. 4(c)), but with $\{011)_{t}$ ferroelectric domains completely absent, grain $\mathrm{B}_{3}$ exhibited a type II core-

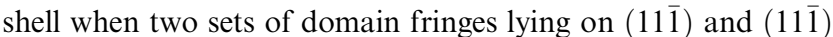
inclining $\sim 109^{\circ}$ (or $71^{\circ}$ ) to each other were discerned, as shown in Fig. 7(a). The FFT-simulated pattern from $Z=$ [011] (inset) shows two sets of satellite spots along the respective reciprocal directions, as indicated. The framed region shown in Fig. 7(b) indicates the (011) projection, approximately $4 \times(1 / 2 \times$ $1.995 \times 1.420) \mathrm{nm}^{2}$ in area, from the supercell of the modulated structure. Assuming that the supercell is based on $p c-\mathrm{BaTiO}_{3}$ $\left(a_{p c}=0.4031 \mathrm{~nm}\right)$, its parameters are therefore $a_{\text {super }} \approx$ $c_{\text {super }}=4.008 \mathrm{~nm}$ (i.e., $a_{p c} \approx 0.1 a_{\text {super }}$ ) and the supercell is $\sim(10)^{3} a_{p c}$ in size.
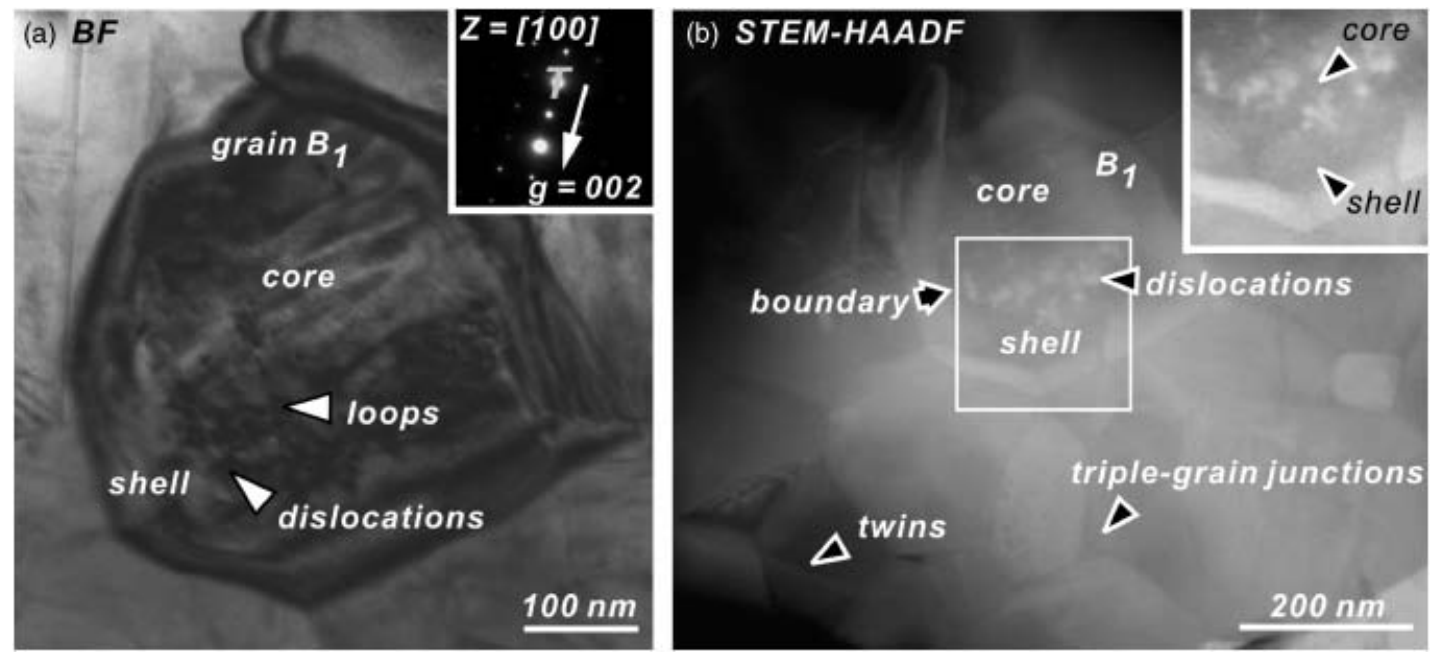

Fig. 5. Type II core-shell structure in sample B, (a) bright field image of grain $\mathrm{B}_{1}$ showing a modulated core and featureless shell, and (b) high-angle annular dark-field (HAADF) image showing atomic contrast of core and shell (transmission electron microscopy). 

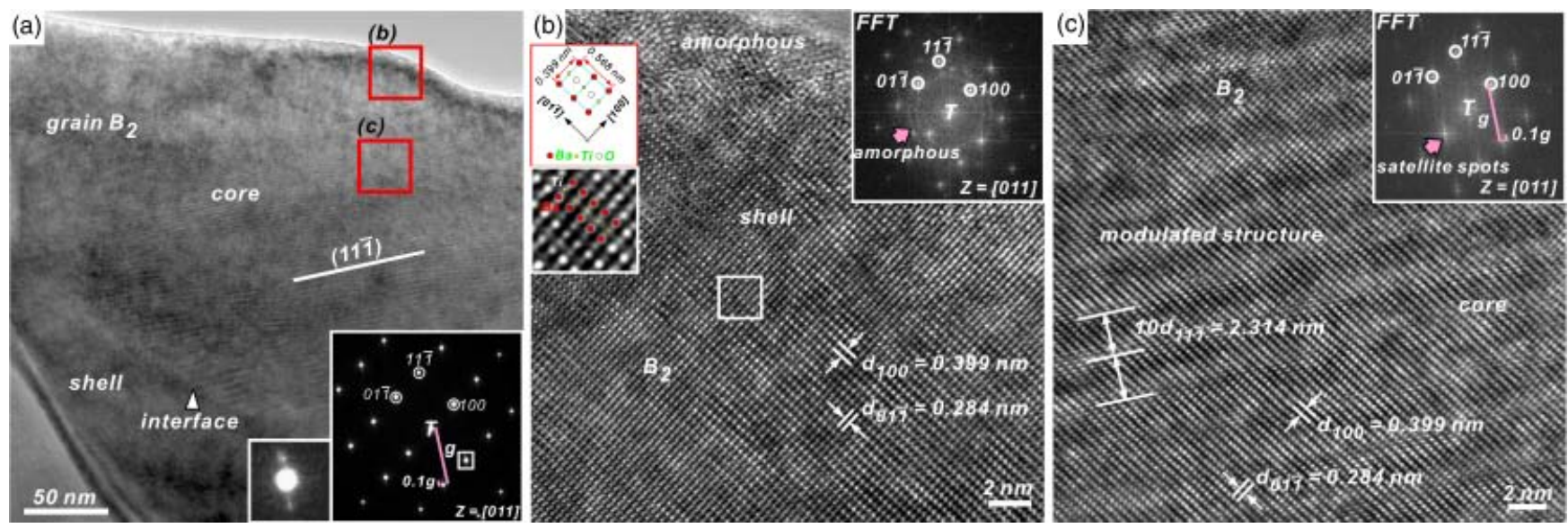

Fig. 6. Modulated core in grain $\mathrm{B}_{2}$ of sample $\mathrm{B}$, (a) bright field image, high-resolution images of showing (b) shell, and (c) modulated core containing superlattice ordering only along $[11 \overline{1}]$ with corresponding selected area diffraction patterns inset (transmission electron microscopy).

\section{Discussion}

In modulated structures, satellite reflections, usually of weaker intensities, arising because of the presence of periodic lattice distortions, are regularly distributed around the fundamental spots in reciprocal space. ${ }^{30,34-36}$ Commensurate and incommensurate $^{35,36}$ superlattice of the displacive type is often found in structural phase transition $^{34}$ in ferroelectrics, antiferroelectrics, ${ }^{32}$ and ferroelastics. ${ }^{38}$

\section{(1) Size of Superlattice}

For crystals with three-dimensional (3D) modulation ${ }^{34,39}$ exhibiting characteristic satellite spots, the incommensurate modulated structure may be expressed as an irrational 3D intersection of a periodic structure in a $(3+n)$-dimensional space. Therefore, any diffraction vectors $(\mathbf{H})$ can be specified by six integers, $h_{1}$ to $h_{6}$, i.e., $3+n$ where $n=3$, as

$$
\mathbf{H}=h_{1} \mathbf{a}^{*}+h_{2} \mathbf{b}^{*}+h_{3} \mathbf{c}^{*}+\mathbf{q}
$$

The modulation is described by the wave vector

$$
\mathbf{q}=h_{4} \mathbf{k}_{1}+{ }_{5} \mathbf{k}_{2}+h_{6} \mathbf{k}_{3}
$$

and $\mathbf{k}_{\mathrm{i}}=\alpha_{\mathrm{i}} \mathbf{a}^{*}+\beta_{\mathrm{i}} \mathbf{b}^{*}+\gamma_{\mathrm{i}} \mathbf{c}^{*}, \mathrm{i}=1 \sim 3$, where $\mathbf{a}^{*}, \mathbf{b}^{*}$, and $\mathbf{c}^{*}$ are the unit vectors in the reciprocal lattice of the basic ( $p c$ perovskite) structure, and $\mathbf{k}_{1}, \mathbf{k}_{2}$, and $\mathbf{k}_{3}$ are fractional wave vectors in the 3D space none of which is describable by an integral linear combination of the others. Thus, it becomes a sixdimensional representation for a three-dimensionally modulated structure. For the $\{111\}$ modulated structure, the coefficients $\alpha_{1}=\beta_{2}=\gamma_{3}=0.58$ are equal, with others being zero.

Cation-deficient wüstite $\left(\mathrm{Fe}_{1-x} \mathrm{O}\right)$ forms cation interstitial-vacancy clusters, ${ }^{37}$ e.g., the Catlow-Fender type of $\left(4 V_{\mathrm{Fe}}^{\prime \prime}, \mathrm{Fe}_{\mathrm{i}}^{\bullet \bullet \bullet}\right)^{5^{\prime}}$, adopting the Kröger-Vink notations and abbreviated to $\mathrm{V}_{4} \mathrm{~T}_{1}$, or Koch-Cohen $\mathrm{V}_{13} \mathrm{~T}_{4}$, having metal interstitials $\left(\mathrm{Fe}_{\mathrm{i}}^{\bullet \bullet \bullet}\right)$ as the principal charge-compensation defects for metal vacancies $\left(V_{\mathrm{Fe}}^{\prime \prime}\right)$ generated in $p \mathrm{O}_{2}$. Its structure has been described ${ }^{35,36}$ as a highly distorted (or paracrystalline) superlattice of $\sim(2.51)^{3} a^{3}$ to $\sim(2.73)^{3} a^{3}$ in size, where $a=$ unit cell repeat of rock salt $\mathrm{FeO}$. The defected $\mathrm{Fe}_{1-x} \mathrm{O}$ structure was displasive modulated by wave vectors $\mathbf{k}_{1}=\alpha \mathbf{a}^{*}, \mathbf{k}_{2}=\beta \mathbf{b}^{*}$, and $\mathbf{k}_{3}=\gamma \mathbf{c}^{*}$ with $\alpha=\beta=\gamma$ lying between 0.37 and $0.40 .{ }^{35,36,40}$ Similar to that in wüstite, the reciprocal lengths of the superlattice in $t-\mathrm{BaTiO}_{3}$ are $\sim 0.58$ (calculated from $(1 / \sqrt{ } 3) \times\left(\boldsymbol{q}_{111}\right) /\left(a_{p c} / a_{\text {super }}\right) \approx(1 / \sqrt{ } 3)$ $\times 0.1 / 0.1)$. It may be described equivalently by a displasive modulation $^{34,41}$ with incommensurate wave vectors $\mathbf{k}_{1}=$ $0.58 \mathbf{a}^{*}, \mathbf{k}_{2}=0.58 \mathbf{b}^{*}$, and $\mathbf{k}_{3}=0.58 \mathbf{c}^{*}$.

\section{(2) Defect Reactions and Formation of Superlattice}

Two types of substitutional defects are possible: (a) acceptor cations substituting for the $\mathrm{Ti}^{4+}$-site, e.g., $\mathrm{Ca}^{2+}$ existing in the
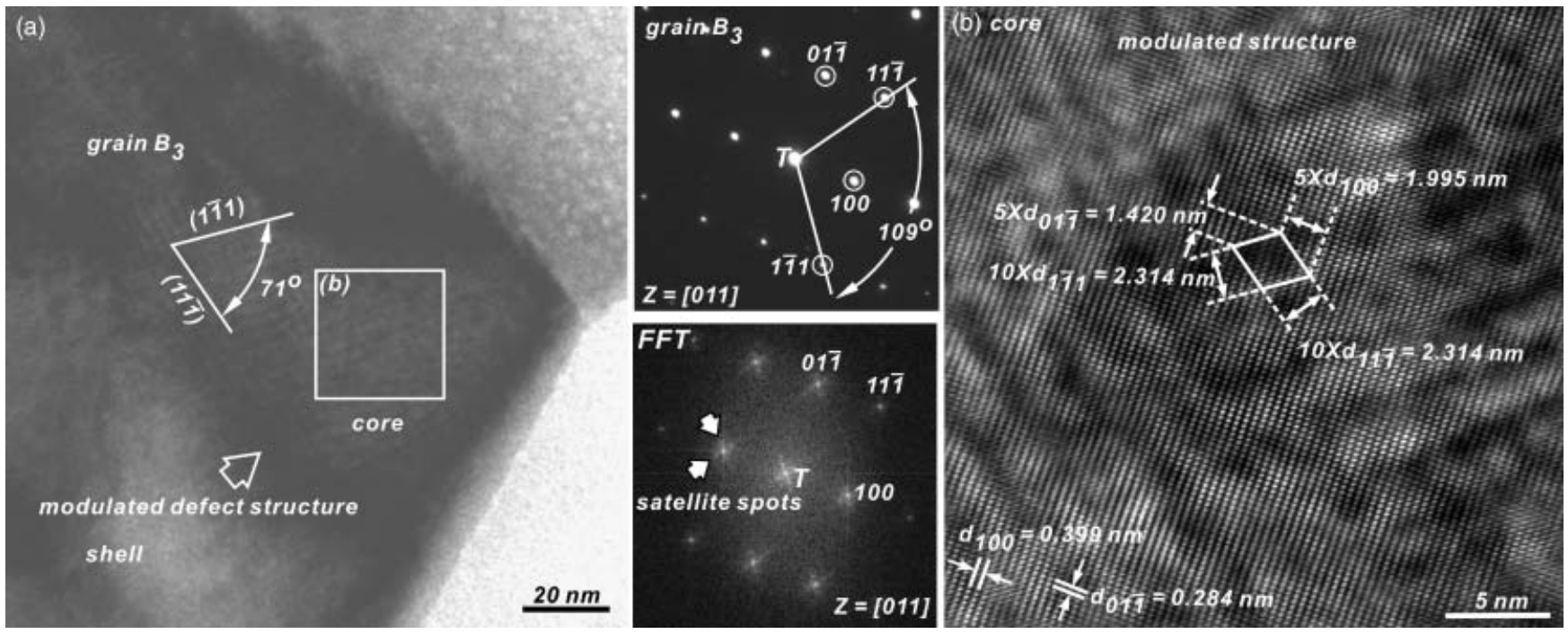

Fig. 7. Grain $B_{3}$ in sample $B$ showing (a) modulated $\{111\}$ domains lying on both $(1 \overline{1} 1)$ and (11) , and (b) high-resolution image revealing the superlattice modulated by wavelength $\lambda=2.314 \mathrm{~nm}$ (transmission electron microscopy). 
initial formulation, ${ }^{23}$ or (b) $\mathrm{Ti}^{4+}$ being reduced to $\mathrm{Ti}^{3+}$ under low $\mathrm{pO}_{2}$.

Under low $p \mathrm{O}_{2}, \mathrm{Ti}^{4+}$ in $\mathrm{BaTiO}_{3}$ is reduced to $\mathrm{Ti}^{3+}$ and becomes a self-doping acceptor; oxygen vacancies $\left(V_{\mathrm{O}}^{\bullet \bullet}\right)$ are generated extrinsically as the principal charge-compensating defect to retain the overall charge neutrality. For Schottky intrinsic behavior in undoped $\mathrm{BaTiO}_{3}$, the defect reaction may be described by

$$
\mathrm{O}_{\mathrm{O}}^{\mathrm{X}} \rightarrow 2 \mathrm{Ti}^{\prime}{ }_{\mathrm{Ti}}+V_{\mathrm{O}}^{\bullet \bullet}+1 / 2 \mathrm{O}_{2}(\mathrm{~g})
$$

Similarly, B-site acceptors in the X7R formulation, e.g., CaO, $\mathrm{MnO}$ in reducing atomspheres, ${ }^{42}$ and amphoteric oxides, ${ }^{4}$ e.g., $\mathrm{Y}_{2} \mathrm{O}_{3}$ form a solid solution with $\mathrm{BaTiO}_{3}$ and generate extrinsically the negative-effective-charged substitutional defects, i.e., $\mathrm{Ca}_{\mathrm{Ti}}^{\prime \prime}, \mathrm{Mn}_{\mathrm{Ti}}^{\prime \prime}$, and $\mathrm{Y}_{\mathrm{Ti}}^{\prime}$ that are also charge compensated by $V_{\mathrm{O}}^{\bullet \bullet} \cdot 1,4,41$

The defect reaction represented by $\mathrm{CaO}$ can be described ${ }^{2}$ by the following equation with the site relation $\mathrm{Ba}: \mathrm{Ti}: \mathrm{O}=1: 1: 3$ in the parent lattice $\mathrm{BaTiO}_{3}$ preserved, viz.,

$$
\mathrm{CaO}+\mathrm{BaO} \rightarrow \mathrm{Ba}_{\mathrm{Ba}}^{\mathrm{X}}+\mathrm{Ca}_{\mathrm{Ti}}^{\prime \prime}+V_{\mathrm{O}}^{\bullet \bullet}+2 \mathrm{O}_{\mathrm{O}}^{\mathrm{X}}
$$

with $\mathrm{Ti}^{4+}$ reduced to $\mathrm{Ti}^{3+}$ under low $\mathrm{pO}_{2}$, substitutional defects containing only a single negative effective charge, i.e., $\mathrm{Ca}_{\mathrm{Ti}}^{\prime}$, are compensated by either singly $\left(V_{\mathrm{O}}^{\bullet}\right)$ or fully $\left(V_{\mathrm{O}}^{\bullet \bullet}\right)$ ionized oxygen vacancies. Similar to wüstite, ${ }^{39}$ but distinctive in the nature of defect species, it is likely that the substitutional defects and oxygen vacancies combine to form defect associates (or sometimes termed complex defects) of $\left(\mathrm{Ti}_{\mathrm{Ti}}^{\prime}, V_{\mathrm{O}}^{\bullet \bullet}\right)^{\bullet}$ or $\left(\mathrm{Ca}_{\mathrm{Ti}}^{\prime \prime}, V_{\mathrm{O}}^{\bullet \bullet}\right)^{\times}$, particularly on a long sintering schedule. Then, the superlattice built on $p c-\mathrm{BaTiO}_{3}$, associated with $\left(V_{\mathrm{O}}^{\bullet \bullet}\right),{ }^{5-8}$ would have been derived from the clustering and ordering of extrinsic defects. As higher Ca reading in the shell is confirmed (Fig. 4(d)), and the structure modulation occurs only in the core (e.g., Figs. 6(c) and 7(b)), the $\left(\mathrm{Ti}_{\mathrm{Ti}}^{\prime}, V_{\mathrm{O}}^{\bullet \bullet}\right)^{\bullet}$ defect associates are likely to be the principal defect species responsible for the incommensurate superlattice. During sintering, the complex defects become ordered crystallographically along $\langle 11 \overline{1}\rangle$ of the basic structure ${ }^{5-8}$ and form a highly distorted lattice ${ }^{34,35}$ of average spacings of $a_{\text {super }} \times a_{\text {super }} \times a_{\text {super }} \approx 4.008 \mathrm{~nm} \times 4.008 \mathrm{~nm}$ $\times 4.008 \mathrm{~nm}$, constituting a supercell $\sim 1000$ times of the size of $t-\mathrm{BaTiO}_{3}$.

Higher $\mathrm{Ca}$ counts in the shell are consistently detected by EDS (Fig. 3(c)) and EELS (Fig. 4(d)). While $\mathrm{Ti}_{\mathrm{Ti}}^{\prime}$ was dispersed over whole $\mathrm{BaTiO}_{3}$ grains in samples (A and $\mathrm{B}$ alike) sintered under low $p \mathrm{O}_{2}, \mathrm{Ca}_{\mathrm{Ti}}^{\prime \prime}$ (or $\mathrm{Ca}_{\mathrm{Ti}}^{\prime}$ ) was limited to the grain surface whose thickness depended on how far into the grains $\mathrm{Ca}^{2+}$ ions have diffused toward the grain interior during sintering. The $\mathrm{Ca}^{2+}$ diffusion distance determined by dwelling at a sintering temperature of $1200^{\circ} \mathrm{C}$ (for $2 \mathrm{~h}$ ) would have been similar for samples A and B. However, an oxygen partial pressure of $\sim 10^{-9}$ atm was apparently not low enough for grains in sample A to convert completely into those containing $\mathrm{Ti}_{\mathrm{Ti}}^{\prime}$ and $V_{\mathrm{O}}^{\bullet \bullet}$ (according to Eq. (3)), with all $\mathrm{Ti}^{4+}$ reduced to $\mathrm{Ti}^{3+}$. Some $\mathrm{BaTiO}_{3}$ grains having retained the characteristic $\{011)$ ferroelectric domains ${ }^{24-26}$ in the core ${ }^{17-22}$ of sample A (Fig. 4(a)) where most of $\mathrm{Ti}^{4+}$ were not reduced to $\mathrm{Ti}^{3+}$, exhibited a type I coreshell; others containing a modulated core became type II. Lowering $p \mathrm{O}_{2}$ further to $\sim 10^{-11}$ atm (sample $\mathrm{B}$ ) had not only successfully reduced $\mathrm{Ti}^{4+}$ to $\mathrm{Ti}^{3+}$ for most part of the grains containing both $\mathrm{Ti}_{\mathrm{Ti}}^{\prime}$ and $V_{\mathrm{O}}^{\bullet \bullet}$ but also significantly increased their concentrations. This had consequently produced a type II core-shell with less distinguishable core-shell interface and exhibiting a wavy, modulated structure (Fig. 6(a)) because of the crystallographically ordered $\left(\mathrm{Ti}_{\mathrm{Ti}}^{\prime}, V_{\mathrm{O}}^{\bullet \bullet}\right)^{\bullet}$ defect clusters in sample B. Re-oxidation at $1000^{\circ} \mathrm{C}$ under higher $p \mathrm{O}_{2}\left(\approx 10^{-5}-10^{-6}\right.$ atm), with $\mathrm{Ti}^{3+}$ reverted to $\mathrm{Ti}^{4+}$ and $\mathrm{Ti}_{\mathrm{Ti}}^{\prime}$ lost, effectively eliminated the defect cluster $\left(\mathrm{Ti}_{\mathrm{Ti}}^{\prime}, V_{\mathrm{O}}^{\bullet \bullet}\right)^{\bullet}$. At the same time, the solute cations within the grains were distributed more homogeneously, ${ }^{20}$ and as they diffused toward the core, the shell thickness increased. The neutral $\left(\mathrm{Ca}_{\mathrm{Ti}}^{\prime \prime}, V_{\mathrm{O}}^{\bullet \bullet}\right)^{\times}$defect associates in the $\mathrm{Ca}^{2+}$-enriched shell were retained, while the singly charged $\left(\mathrm{Ca}_{\mathrm{Ti}}^{\prime}, V_{\mathrm{O}}^{\bullet \bullet}\right)^{\bullet}$ complexes re-oxidized to $\left(\mathrm{Ca}_{\mathrm{Ti}}^{\prime \prime}, V_{\mathrm{O}}^{\bullet \bullet}\right)^{\times}$. The diffusive core-shell interface, resulting from the lattice diffusion of both $\mathrm{O}^{2-}$ and $\mathrm{Ca}^{2+}$ toward the core, would then depend on the $p \mathrm{O}_{2}$ used for re-oxidation. A higher $p \mathrm{O}_{2}$ and/or a longer re-oxidation may alter the core-shell to consist of a paraelectric shell with increased thickness containing $\left(\mathrm{Ca}^{\prime \prime}{ }_{\mathrm{Ti}}, V_{\mathrm{O}}^{\bullet \bullet}\right)^{\times}$, and a core still with major defect clusters $\left(\mathrm{Ti}^{\prime}{ }_{\mathrm{Ti}}, V_{\mathrm{O}}^{\bullet \bullet}\right)^{\bullet}$ but of diminishing size. A shell thickness ${ }^{8}$ of $\sim 25$ to $\sim 50-120 \mathrm{~nm}$ (Figs. 4(a-c)) therefore depends on how long the MLCC chips are subjected to annealing in $10^{-5}-10^{-6} \mathrm{~atm}$ at $1000^{\circ} \mathrm{C}$ and cooling to room temperature. Of course, $\mathrm{Ca}^{2+}$ distribution in grains would be further homogenized ${ }^{20}$ by re-oxidation and this has also increased the shell thickness. The dielectric behavior of MLCCs is modified $^{43}$ accordingly.

\section{(3) Evolution of Core-Shell}

The disappearance of wavelike fluctuations at the core-shell boundary of grains in sample A (e.g., Fig. 4(c)) infers that clustering of defects containing oxygen vacancies has been suppressed in the shell (of $\sim 50-120 \mathrm{~nm}$ ). Diffusion of solutes, i.e., $\mathrm{Zr}^{4+}$, toward the grain interior was thought ${ }^{20}$ to occur during the evolution of a core-shell in $\mathrm{ZrO}_{2}$-doped $\mathrm{BaTiO}_{3}$ sintered in

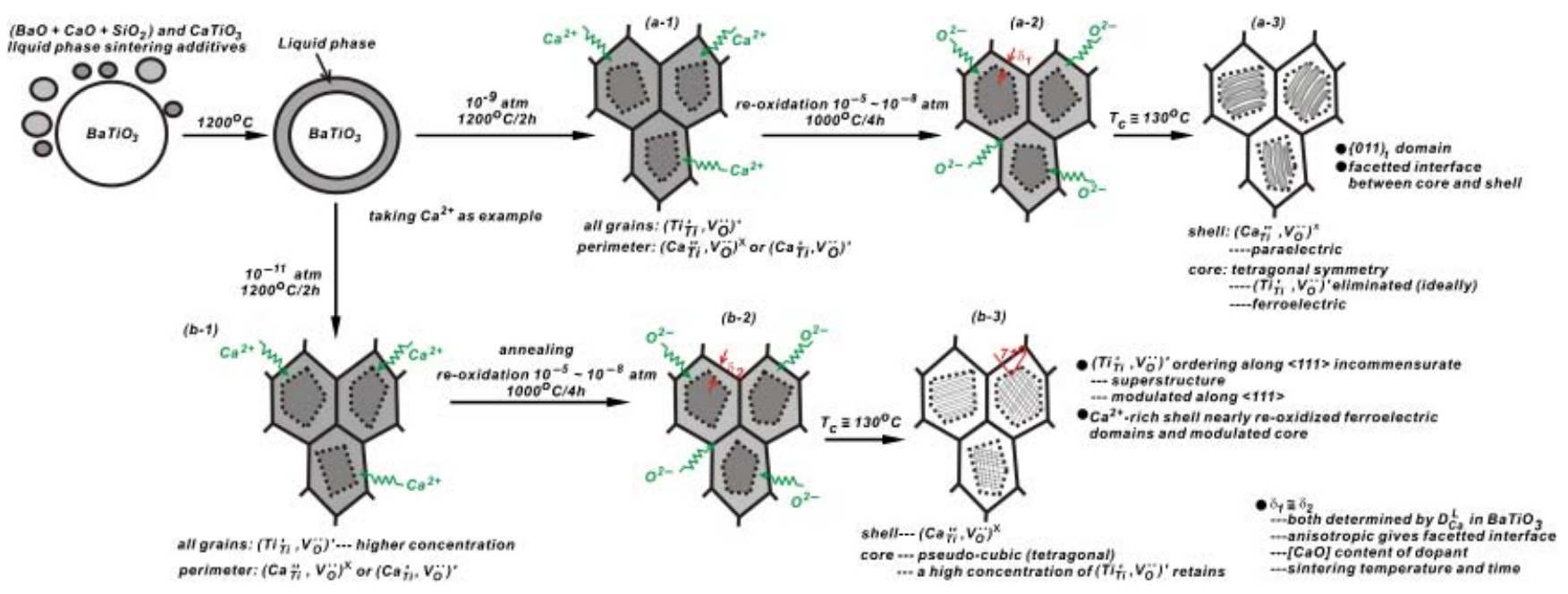

Model of formation of core-shell and modulated structure

Fig. 8. Schematic diagrams illustrating the evolution of a core-shell in X7R-formulated $\mathrm{BaTiO}_{3}$ ceramics, (a) type I, and (b) type II. 
air. Consequently, ferroelectric domains had disappeared in the paraelectric shell of $\mathrm{Ba}(\mathrm{Ti}, \mathrm{Zr}) \mathrm{O}_{3} .{ }^{17-20}$ Similarly, an acceptorcation $\mathrm{Ca}^{2+}$ forming solid solution ${ }^{1} \mathrm{Ba}(\mathrm{Ti}, \mathrm{Ca}) \mathrm{O}_{3}$ makes the shell paraelectric and featureless ${ }^{17-22}$ (Fig. 3(a)). Diffusion of $\mathrm{Ca}^{2+}$ inward resulting in an inhomogeneous distribution is supported by EDS and EELS (Figs. 3(c), 4(d), and (e), as discussed previously); similar to the $\mathrm{Zr}^{4+}$-doped compositions, its inhomogeneity may then account for the core-shell formation. Oxygen vacancies generated under low $p \mathrm{O}_{2}$ sintering are responsible for formation of the modulated core when oxygen diffusion during re-oxidation gradually diminishes it. The modulated domains lying in $\{111\}$ are consistent with the $\{111\}$ growth twins containing oxygen vacancies ${ }^{28,30}$ at the twin plane whose formation was stimulated by sintering under low $p \mathrm{O}_{2}$, e.g., Ar atmosphere. ${ }^{44}$ The diffusive core-shell interface would be a transition region where newly oxidized modulated coreforming ferroelectric domains co-exist with a paraelectric shell of a higher solute content, and a modulated core of a lower solute content.

Based on microchemical analysis by EDS and EELS, a model illustrated schematically in Fig. 8 is proposed to account for core-shell evolution, both types I and II, in the X7R-formulated $\mathrm{BaTiO}_{3}$ ceramics. Shell thicknesses $\delta_{1}$ and $\delta_{2}$, shown in Figs. 8(a2 ) and (b-2), of samples A and B, respectively, are determined by the lattice diffusion coefficient of $\mathrm{Ca}^{2+}, \mathrm{D}_{\mathrm{Ca}}^{\mathrm{L}}$, in $\mathrm{BaTiO}_{3}$. They would have been very similar because of the same doping levels. However, the blurred interface in sample B has made the shell thickness ambiguous (e.g., Fig. 4(c)). As grains of sample A (type I core-shell) have been re-oxidized completely, the shell thickness is determined by $\mathrm{Ca}^{2+}$ inward diffusion. On the other hand, grains in sample B (type II core-shell) were only partially re-oxidized. The shell therefore appears to extend beyond the core-shell interface demarcated by the concentration of $\mathrm{Ca}^{2+}$ when $\mathrm{O}^{2-}$ diffuses at a faster rate further into the grains and has made the core to re-oxidize progressively, and the interface blurred. However, the type II core containing $\left(\mathrm{Ti}^{\prime}{ }_{\mathrm{Ti}}, V_{\mathrm{O}}^{\bullet \bullet}\right)^{\bullet}$ clusters still remains oxygen deficient.

\section{Conclusions}

The inhomogeneous distribution of acceptor-cation $\mathrm{Ca}^{2+}$ is responsible for the core-shell grains in the $\mathrm{X} 7 \mathrm{R}$-formulated $\mathrm{BaTiO}_{3}$ ceramics. The $\mathrm{Ca}^{2+}$ inhomogeneity was due to the lattice diffusion of $\mathrm{Ca}^{2+}$ into $\mathrm{BaTiO}_{3}$ grains upon sintering. Most of the grains in sample A sintered under $p \mathrm{O}_{2} \approx 10^{-9}$ atm were re-oxidized in the re-oxidation step and resumed to a shell containing predominantly the $\left(\mathrm{Ca}_{\mathrm{Ti}}^{\prime \prime}, V_{\mathrm{O}}^{\bullet \bullet}\right)^{\times}$defect associates. Grains in sample $\mathrm{B}$ sintered in $\mathrm{pO}_{2} \approx 10^{-11}$ atm, however, were not fully re-oxidized and left behind a core containing the $\left(\mathrm{Ti}_{\mathrm{Ti}}^{\prime}, V_{\mathrm{O}}^{\bullet \bullet}\right)^{\bullet}$ defect associates. These defects, that became clustered and ordered, not only resulted in an incommensurate superlattice with ordering along $\langle 11 \overline{1}\rangle$ in the core but also obscured the core-shell interface initially demarcated by the $\mathrm{Ca}^{2+}$ inhomogeneity.

A model is proposed to account for the evolution of a core-shell in the X7R formulation. It is suggested that this model is equally applicable to MLCC ceramics based on $\mathrm{BaTiO}_{3}$ compositions doped with other acceptor and amphoteric oxides.

\section{Acknowledgment}

Thanks are due to Ferro Electronic Material Systems, Penn Yan, NY, for funding support.

\section{References}

${ }^{1}$ Y. H. Han, J. B. Appleby, and D. M. Smyth, "Calcium as an Acceptor Impurity in $\mathrm{BaTiO}_{3}$," J. Am. Ceram. Soc., 70 [2] 96-100 (1987).

${ }^{2}$ N. H. Chan, R. K. Sharma, and D. M. Smyth, "Nonstoichiometry in Acceptor-Doped $\mathrm{BaTiO}_{3}$," J. Am. Ceram. Soc., 65 [3] 167-70 (1982).
${ }^{3}$ Q. Feng and C. J. McConville, "Weak-Beam Dark-Field Microscopy of Complex Stress States in X7R-Type $\mathrm{BaTiO}_{3}$ Dielectric Core-Shell Structures," J. Am. Ceram. Soc., 87 [10] 1945-51 (2004).

${ }^{4}$ Y. Tsur, A. Hitomi, I. Scrymgeour, and C. A. Randall, "Site Occupancy of Rare-Earth Cations in $\mathrm{BaTiO}_{3}$, , Jpn. J. Appl. Phys., 40 [1, Part 1] 255-8 (2001)

${ }^{5}$ G. Y. Yang, E. C. Dickey, C. A. Randall, M. S. Marshall, and L. A. Mann, "Modulated and Ordered Defect Structures in Electrically Degraded Ni-BaTiO Multilayer Ceramic Capacitors," J. Appl. Phys., 94 [9] 5990-6 (2003).

${ }^{6}$ D. I. Woodward, I. M. Reaney, G. Y. Yang, E. C. Dickey, and C. A. Randall, "Vacancy Ordering in Reduced Barium Titanate," Appl. Phys. Lett., 84 [23] 4650 2 (2004)

${ }^{7}$ G. Y. Yang, E. C. Dickey, C. A. Randall, D. E. Barberm, P. Pinceloup, M. A. Handerson, R. A. Hill, J. J. Beeson, and D. J. Skamser, "Oxygen Nonsotichiometry and Dielectric Evolution of $\mathrm{BaTiO}_{3}$. Part I-Improvement of Insulation Resistance with Reoxidation," J. Appl. Phys., 96 [12] 7492-9 (2004).

${ }^{8}$ G. Y. Yang, G. D. Lian, E. C. Dickey, C. A. Randall, D. E. Barber, P. Pinceloup, M. A. Handerson, R. A. Hill, J. J. Beeson, and D. J. Skamser, "Oxygen Nonsotichiometry and Dielectric Evolution of $\mathrm{BaTiO}_{3}$. Part II-Insulation Resistance Degradation Under Applied de Bias," J. Appl. Phys., 96 [12] 7500-8 (2004)

${ }^{9}$ H. Chazono and H. Kishi, "dc-Electrical Degradation of the BT-Based Material for Multilayer Ceramic Capacitor with Ni internal Electrode: Impedance Analysis and Microstructure," Jpn. J. Appl. Phys., 40 [9B, Part 1] 5624-9 (2001).

${ }^{10}$ R. Waser, T. Baiatu, and K. H. Härdtl, "dc-Electrical Degradationof Perovskite-Type Titanates: I, Ceramics,” J. Am. Ceram. Soc., 73 [6] 1645-53 (1990).

${ }^{11}$ R. Waser, T. Baiatu, and K. H. Härdtl, "dc Electrical Degradationof Perovskite-Type Titanates: II, Single Crystals," J. Am. Ceram. Soc., 73 [6] 1654-62 (1990)

${ }^{12}$ T. Baiatu, R. Waser, and K. H. Härdtl, "dc Electrical Degradationof Perovskite-Type Titanates: III, A Model of Mechanism," J. Am. Ceram. Soc., 73 [6] 1663-73 (1990).

${ }^{13}$ A. Rečnik, J. Bruley, M. Mader, D. Kolar, and M. Rühle, "Structural and Spectroscopic Investigation of (111) Twins in $\mathrm{BaTiO}_{3}$, " Philos. Mag., B70 [5] 1021-34 (1994).

${ }^{14}$ O. Eibl, P. Pongratz, and P. Skalicky, "Formation of (111) Twins in $\mathrm{BaTiO}_{3}$ Ceramics," J. Am. Ceram. Soc., 70 [8] C195-7 (1987).

${ }^{15}$ E. Hamada, W. S. Cho, and K. Takayanagi, "Nanotwins in $\mathrm{BaTiO}_{3}$ Nanocrystals," Philos. Mag. A, 77 [5] 1301-8 (1998).

${ }^{16}$ I. E. Grey, C. Li, L. M. D. Cranswick, R. S. Roth, and T. A. Vanderah, "Structure Analysis of the $6 \mathrm{H}-\mathrm{Ba}\left(\mathrm{Ti}, \mathrm{Fe}^{3+}, \mathrm{Fe}^{4+}\right) \mathrm{O}_{3-\delta}$ Solid Solution," J. Solid Stat. Chem., 135 [2] 312-21 (1998).

${ }^{17}$ B. S. Rawal, M. Kahn, and W. R. Buessem, "Grain Core-Shell Structure in $\mathrm{BaTiO}_{3}$-Based Dielectrics"; pp. 172-88 in Grain Boundary Phenomena in Electronic Ceramics, Advanced Ceramics, Vol. 1, Edited by L. M. Levinson. American Ceramic Society, Columbus, OH, 1981.

${ }^{18}$ D. Hennings and G. Rosenstein, "Temperature-Stable Dielectric Based on Chemically Inhomogeneous $\mathrm{BaTiO}_{3}$, , J. Am. Ceram. Soc., 67 [4] 249-54 (1984).

${ }^{19}$ T. R. Armstrong and R. C. Buchanan, "Influence of Core-Shell Grains on the Internal Stress State and Permittivity Response of $\mathrm{ZrO}_{2}$-Modified $\mathrm{BaTiO}_{3}$, , J. Am. Ceram. Soc., 73 [5] 1268-73 (1990).

${ }^{20}$ H. Y. Lu, J. S. Bow, and W. H. Deng, "Core-Shell Structures in $\mathrm{ZrO}_{2}-\mathrm{Mod}$ ified $\mathrm{BaTiO}_{3}$ Ceramics," J. Am. Ceram. Soc., 73 [12] 3562-8 (1990).

${ }^{21}$ C. A. Randall, S. F. Wang, D. Laubscher, J. P. Dougherty, and W. Huebner, "Structure Property Relationships in Core-Shell $\mathrm{BaTiO}_{3}-\mathrm{LiF}_{\text {Ceramics," }} \mathrm{J} . \mathrm{Ma}$ ter. Res., 8 [4] 871-9 (1993).

${ }^{22}$ J. S. Kim and S. J. L. Kang, "Formation of Core-Shell Structure in the BaT$\mathrm{iO}_{3}-\mathrm{SrTiO}_{3}$ System," J. Am. Ceram. Soc., 82 [4] 1085-8 (1999).

${ }^{23}$ H. D. Park, J. D. Nance, M. S. H. Chu, and Y. Avniel, "Multilayer Ceramic Chip Capacitors With High Reliability Compatible With Nickel Electrodes"; U.S Patent No. 6,185,087, Feb. 6, 2001

${ }^{24}$ Y. C. Wu, D. E. McCauley, M. S. H. Chu, S. F. Wang, and H. Y. Lu, "Second Phases in X7R Formulated $\mathrm{BaTiO}_{3}$ Base-Metal-Electrode Multilayer Capacitor Dielectrics," Paper I-3, Ceramic Multilayer Capacitors and substrates-A Ferro Technical Symposium, Taipei, Taiwan, June 30, 2006.

${ }^{25}$ Y. H. Hu, H. M. Chan, X. W. Zhang, and M. P. Harmer, "Scanning Electron Microscopy and Transmission Electron Microscopy Study of Ferroelectric Domains in Doped $\mathrm{BaTiO}_{3}$, , J. Am. Ceram. Soc., 69 [8] 594-602 (1986).

${ }^{26}$ J. F. Chou, M. H. Lin, and H. Y. Lu, "Ferroelectric Domains in PressurelessSintered $\mathrm{BaTiO}_{3}, "$ Acta Mater., 48 [13] 3569-79 (2000).

${ }^{27}$ S. Amelinckx and J. van Landyut, "The Study of Planar Interfaces by Means of Electron Microscopy"; pp. 107-51 in Diffraction and Imaging Techniques in Materials Science, 2nd Edition, Edited by S. Amelinckx, R. Gevers, and J. van Landyut. North-Holland, Amsterdam, The Netherlands, 1978.

${ }^{28}$ J. K. Liou, M. H. Lin, and H. Y. Lu, "Crystallographic Faceting in Pressureless-Sintered $\mathrm{BaTiO}_{3}$, , J. Am. Ceram. Soc., 85 [12] 2931-7 (2002).

${ }^{29}$ A. Rečnik, J. Bruley, W. Mader, D. Kolar, and M. Rühle, "Structural and Spectroscopic Investigation of (111) Twins in Barium Titanate," Philos. Mag., B70 [5] 1021-34 (1994).

${ }^{30}$ P. R. Buseck and D. R. Veblen, "Mineralogy"; pp. 308-77 in High Resolution Transmission Electron Microscopy and Associated Techniques, Edited by P. Buseck, J. Cowley, and L. R. Eyring. Oxford University Press, Oxford, 1992.

${ }^{31}$ C. L. Jia and K. Urban, "Atomic-Resolution Measurement of Oxygen Concentration in Oxide Materials," Science, 303, 2001-4 (2004).

${ }^{32}$ L. A. Bursill, X. Fan, and J. Peng, "Fractal Analysis of Crystalline Surfaces at Atomic Resolution," Philos. Mag. A, 64 [2] 443-64 (1991).

${ }^{33}$ D. B. Williams and C. B. Carter, Transmission Electron Microscopy, pp. 476 9. Plenum, New York, 1996.

${ }^{34}$ A. Janner and T. Janssen, "Symmetry of Periodically Distorted Crystals," Phys. Rev. B, 15 [2] 643-58 (1977). 
${ }^{35}$ T. R. Welberry and A. G. Christy, "A Paracrystalline Description of Defect Distributions in WüStite, $\mathrm{Fe}_{1-\mathrm{X}} \mathrm{O}$," J. Solid Stat. Chem., 117 [2] 398-406 (1995).

${ }^{36}$ T. R. Welberry and A. G. Christy, "Defect Distribution and the Diffuse X-ray Diffraction Pattern of Wüstite, $\mathrm{Fe}_{1-x} \mathrm{O}$," Phys. Chem. Minerasl., 24 [1] 24-38 (1997).

${ }^{37}$ C. R. A. Catlow, "Defect Clustering in Non-Stoichiometric Oxides"; pp. 6198 in Nonstoichiometric Oxides, Edited by O. T. Sørensen. Academic Press, New York, 1981.

${ }^{38}$ R. L. Withers and S. Schmid, "A TEM and Group Theoretical Study of $\alpha$ $\mathrm{PbO}$ and its Low-Temperature Improper Ferroelastic Phase Transition," J. Solid State Chem., 113 [2] 272-80 (1994).

${ }^{39}$ P. M. DeWolff, "The Pseudo-Symmetry of Modulated Crystal Structure," Acta Cryst., A30 [6] 777-85 (1974).
${ }^{40}$ A. Yamamoto, "Modulated Structure of Wüstite $\left(\mathrm{Fe}_{1-x} \mathrm{O}\right)$ (Three-Dimensional Modulation," Acta Cryst., B38, 1451-6 (1982).

${ }^{41}$ D. Viehland, "TEM Study of High-Zr-Content Lead Zirconate Titanate," J. Appl. Phys., 52 [2] 778-91 (1995).

${ }^{42}$ H. T. Langhammer, T. Müller, A. Polity, K. H. Felgner, and H. P. Abicht, "On the Crystal and Defect Structure of Mn-Doped Barium Titanate Ceramics," Mater. Lett., 26 [4-5] 205-10 (1996).

${ }^{43}$ D. E. McCauley, M. S. H. Chu, and M. H. Megherhi, " $\mathrm{pO}_{2}$ Dependence of the Diffuse Phase Transition in Base Metal Capacitor Dielectrics," J. Am. Ceram. Soc., 89 [1] 193-201 (2006).

${ }^{44}$ Y. C. Wu, C. C. Lee, D. E. McCauley, M. S. H. Chu, and H. Y. Lu, "The $\{111\}$ Growth Twins in $\mathrm{BaTiO}_{3}$ Ceramics," J. Am. Ceram. Soc., 89 [5] 1679-86 (2006). 
Copyright of Journal of the American Ceramic Society is the property of Blackwell Publishing Limited and its content may not be copied or emailed to multiple sites or posted to a listserv without the copyright holder's express written permission. However, users may print, download, or email articles for individual use. 